\title{
Immune Modulation and Treatment of Human Papilloma Virus-Related Warts with Energetics of Living Systems Acupuncture
}

\author{
Rom Brustin, MSc, Martine Toledano, MD, Tal Geffen, $\mathrm{PhD}^{3}$, Raia Goona, RN, MA, \\ Malka Hochberg, PhD, ${ }^{2}$ Bilha Kreisberg, RN, MA, Sari Murad, MD, and Jacob Pitcovski, PhD ${ }^{1,3}$
}

\begin{abstract}
Background: Cutaneous warts are small skin lesions formed as a result of infection by the human papilloma virus (HPV). In the lesion, viral manipulation creates a microenvironment that favors virus survival and reproduction. Most lesions eventually regress, probably as a result of a Th1-mediated immune response. However, some warts fail to regress and become persistent.

Objective: The efficacy of treatment of persistent HPV-caused warts with Energetics of Living Systems acupuncture and monitored immune system involvement was tested.

Methods: Eighteen patients with persistent warts were recruited for the study; 9 received acupuncture treatment and 9 received placebo. Each patient was treated 4 times.

Results: Clinical success was defined as total clearance of all lesions with no recurrence for 3 months. In the treatment group, clinical success was $36.6 \%$ versus $0 \%$ in the placebo group. In the treatment group, the level of interleukin (IL)-10 decreased. In a comparison of patients with cleared warts and overall patients with nonresponding warts, different expression levels of IL- 8 , IL-10, tumor necrosis factor- $\alpha$, IL- 6 , and interferon- $\gamma$ were found, although these differences were not always statistically significant. Trends of differences (not significant) were observed in leukocyte levels. Acupuncture eliminated persistent warts in some of the patients, along with inducing changes in immunologic parameters.

Conclusions: Taking the clinical and immunologic outcomes together, clearance of persistent warts following acupuncture might be due to a shift toward a Th1 immune response, or an anti-inflammatory effect against the lesion-induced microenvironment.
\end{abstract}

Keywords: Papilloma Virus, Warts Treatment, Acupuncture, Energetics of Living Systems, Immune Response

\section{INTRODUCTION}

$\mathbf{T}$ O DATE, MORE THAN 120 TYPES of human papilloma virus (HPV) that cause warts in humans have been identified. It is estimated that $20 \%$ of the population will develop symptoms, more commonly during childhood. Most lesions regress spontaneously without treatment as a result of a Th1-cell-mediated immune response, ${ }^{1}$ followed by immune memory that protects the host from future infection. Chronic persistent warts caused by high-risk HPV types pose a threat of developing into malignancies, especially in the genital tract. Moreover, non-high-risk HPV types, which, until recently were thought to generate benign lesions, have been found in cancer tumors that are not

\footnotetext{
${ }^{1}$ Department of Biotechnology, Tel Hai College, Upper Galilee, Israel.

${ }^{2}$ Hadassah-Hebrew University Medical Center, Jerusalem, Israel.

${ }^{3}$ MIGAL_Galilee Technology Center, Kiryat Shmona, Israel.
} 
conventionally associated with HPV infection. ${ }^{2}$ There is an armamentarium of wart treatments, most of which are aimed to eliminate signs and symptoms. However, some warts fail to regress, and there is a tendency toward recurrence even after treatment that has been considered successful.

Efficient wart treatment should be able to resolve a large array of warts painlessly in 1-3 treatment sessions. There should be no need to treat each lesion separately, nor should there be any scarring. The treatment should offer HPV immunity, and be cost-efficient and available to all patients. ${ }^{3}$ One treatment that might meet all of these criteria is acupuncture, and two such treatments have been reported: one as a case report of 1 patient using traditional acupuncture, ${ }^{4}$ and the other using auricular acupuncture. ${ }^{5}$

Acupuncture involves the insertion of thin needles through a patient's skin at precise points (acupuncture points) to achieve biologic changes that are meant to improve health and well-being. There are numerous approaches in acupuncture. ${ }^{6}$ The approach used in the present study was the Energetics of Living Systems (ELS) approach. ELS is a form of systems theory developed in the West by Dr. Maurice Mussat that incorporates knowledge of ancient texts and a contemporary understanding of mathematics and biology. ${ }^{7,8}$ Scientific reports of the implementation of acupuncture for clinical conditions include back pain, ${ }^{9}$ migraine ${ }^{10}$ recovery from stroke, ${ }^{11}$ anxiety and depression, ${ }^{12}$ insomnia, ${ }^{13}$ schizophrenia, ${ }^{14}$ and gynecologic complications. ${ }^{15}$

The efficacy of acupuncture for the treatment of conditions that involve the immune system has been reported for allergies, ${ }^{16}$ pain relief, ${ }^{17}$ arthritis, ${ }^{17}$ allergic rhinitis, ${ }^{18}$ asthma, ${ }^{19}$ and inflammation. ${ }^{20}$ Immune responses could be influenced by acupuncture treatment, mainly via induction of an anti-inflammatory effect. ${ }^{21}$ Acupuncture treatment has shown clinical benefits in patients with pathologies associated with Th1/Th2 responses, ${ }^{22-24}$ Th1 along with a reduction in tumor necrosis factor $-\alpha(\mathrm{TNF}-\alpha)$ as in rheumatoid arthritis, ${ }^{22}$ and Th2 along with a reduction in interleukin (IL)-10 and IL-4, such as in allergy and asthma. ${ }^{25}$ In addition, similar techniques have shown clinical efficacy in immunologically opposite TH1/TH2 conditions. ${ }^{26}$

HPV infection, and in particular chronic persistent infection, involves viral modulation of the immune microenvironment within the lesion (wart). ${ }^{27,28}$ This viral immune manipulation includes primarily a shift toward a Th2 response with an increase in cytokines such as IL-10, which is inefficient at clearing the infection. ${ }^{28,29}$

It is logical to assume that, if acupuncture treatment can restore the balance of the Th1/Th2 response in Th2-related diseases as noted, it may be possible to do so in the case of chronic HPV infection. The objectives of this study were to test the efficacy of ELS acupuncture as a treatment for persistent HPV warts and to determine the immune response following the treatment.

\section{MATERIALS AND METHODS}

The research protocol was approved by the Hadassah local ethics committee (File Number 0199-12-HMO). Written informed consent, according to the Declaration of Helsinki, was obtained from all participants.

\section{Patients}

Criteria for inclusion were as follows: adults older than 18 years in the range of 20-70 years, with a median of 40 years. All patients had chronic cutaneous warts for 2 years or more and had tried unsuccessfully noninvasive conventional treatments. Patients had no known psychiatric or lifethreatening conditions. Eighteen participants were randomly assigned to 2 groups: one group received acupuncture treatment and the other placebo treatment in a singleblinded, crossover study protocol. Participants were informed about the study protocol but not about the groups that they would be assigned to. Participants were allowed to cross over to the acupuncture group after four sessions of placebo.

\section{Treatment}

Acupuncture and placebo groups received four 30minutes treatment sessions, given at 1-week intervals.

Acupuncture treatment. Acupuncture was performed with the use of 25/30-mm, steel-shaft copper-handled needles $\left(\right.$ Best $\left.^{\mathrm{TM}}\right)$, at a transverse angle of insertion of $\sim 15^{\circ}$. Acupuncture points SP 6 (Sanyinjiao), LR 13 (Zhang Men or Zhangmen), LU 6 (Kongzui), ST 36 (Zusanli), LI 10 (Shousanli), GV 3 (Yao Yang Guan), and CV 12 (Zhong Wan) were treated bilaterally (Fig. 1). This formula of points is the ELS method of reseating the Tai Yin system that, according to Traditional Chinese Medicine, controls immunologic and skin functions.

Placebo treatment. The placebo treatment was performed on the participant's back at seven points in the central trunk while the participant was lying on his/her stomach, unable to see the treatment. An acupuncture needle was used to create a prick sensation, but no needle was actually inserted (Fig. 1).

Treatment efficacy. Clinical efficacy of the treatment or placebo acupuncture was evaluated by a dermatologist $\sim 1$ week after the last session. Final efficacy was determined 3 months after the last session by telephone follow-up. (Fig. 1)

\section{Immunologic Tests}

Blood samples. Blood samples were collected before each treatment. Part of the blood was centrifuged and the serum was separated out. Blood $(5 \mathrm{~mL})$ was added to a 

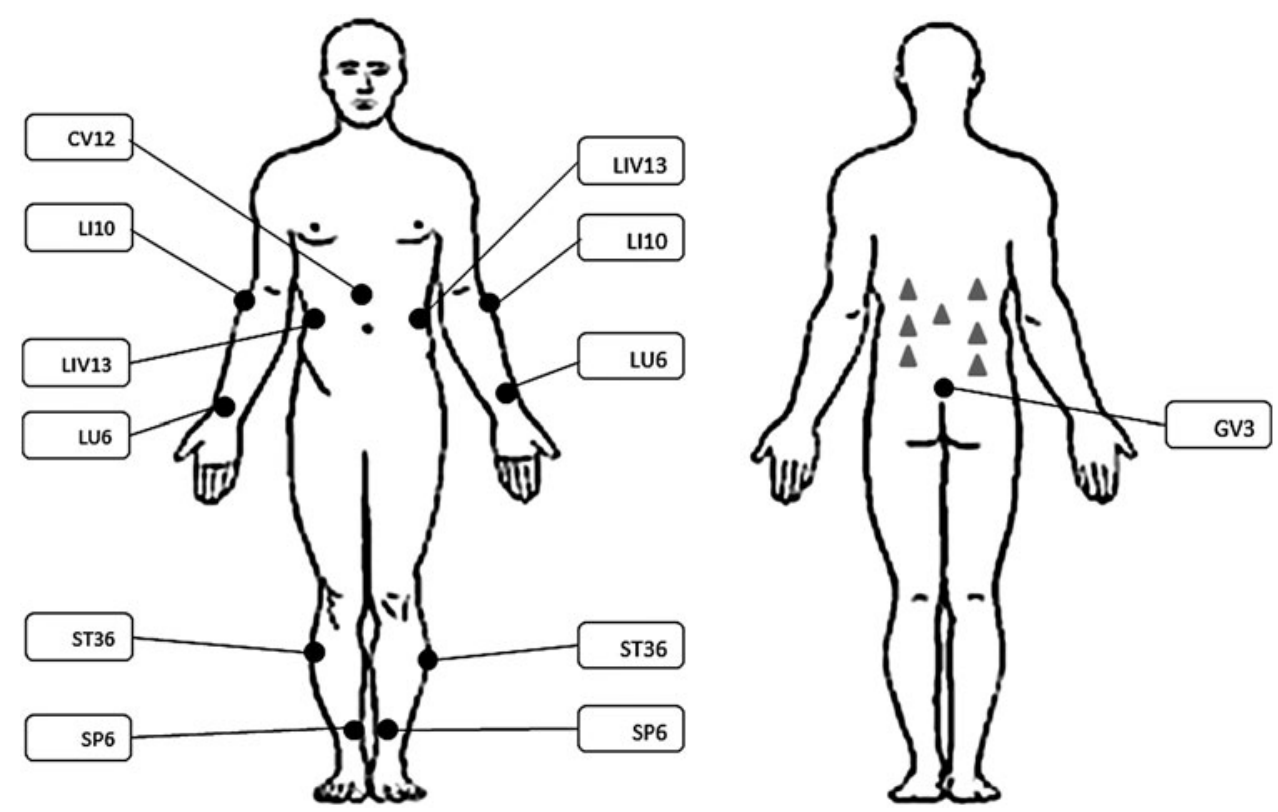

FIG. 1. Acupuncture points and placebo points used in the experiment. Acupuncture points $(\bullet)$. Placebo points $(\boldsymbol{\Delta})$.

mixture of $5 \mathrm{~mL}$ of phosphate buffered saline (PBS) and $5 \mathrm{~mL}$ of Ficoll. ${ }^{\circledR}$ Samples were centrifuged at $1000 \mathrm{~g}$ for 5 minutes. Leukocytes were separated, $10 \mathrm{~mL}$ of PBS was added, and samples were centrifuged at $1000 \mathrm{~g}$ for $5 \mathrm{~min}$ utes. Supernatant was discarded, and the cells were suspended in $5 \mathrm{~mL}$ of PBS. Cells were kept overnight on ice before analysis was performed. Serum samples were stored at $-20^{\circ} \mathrm{C}$ until analysis.

Enzyme-linked immunosorbent assay. The serum values of IL-1, interferon (IFN)- $\gamma$, TNF- $\alpha$, IL-6, IL-8, and IL10 were determined by enzyme-linked immunosorbent assay (ELISA) using a commercial kit (Mini ELISA Development Kit, PeproTech ${ }^{\mathrm{TM}}$ ), according to the manufacturer's instructions. Color development was monitored with the use of an ELISA reader at $405 \mathrm{~nm}$ with wavelength correction set at $650 \mathrm{~nm}$. Results were analyzed by Excel software.

Fluorescence-activated cell sorting. One million cells were added to each of five test tubes, and $1 \mathrm{~mL}$ of fluorescence-activated cell-sorting buffer (PBS, $0.5 \%-1 \%$

Table 1. Clinical Results

\begin{tabular}{lcc}
\hline Group & Positive clinical result & a \\
\hline Acupuncture & $4 / 11$ & 36.3 \\
Placebo & $0 / 9$ & 0 \\
\hline
\end{tabular}

Note: Chi-squared test $p=0.007$.

${ }^{\mathrm{a}}$ Number of patients in which the lesions totally cleared/number of patients participating in the treatment. Two patients crossed over to the acupuncture group, bringing this group number to 11 patients. w/v bovine serum albumin, $0.1 \%$ w/v sodium azide) was added. Samples were centrifuged at $1000 \mathrm{~g}$ for 5 minutes, the supernatant was discarded, and the procedure was repeated twice. A mix of antibodies (PE/Cy7 anti-human CD45, PE anti-human CD4, FITC anti-human CD8, and PerCP-Cy5.5 anti-human CD25; Biolegend ${ }^{\mathrm{TM}}$ ) was added according to the manufacturer's instructions. Samples were incubated for 1 hour on ice, washed and suspended in $1 \mathrm{~mL}$ of PBS. Cells were run in a BD FACSAria ${ }^{\mathrm{TM}}$ II flow cytometer. Results were analyzed by FCS Express software $\left(\right.$ De Novo $\left.{ }^{\mathrm{TM}}\right)$.

\section{Statistical Analysis}

Statistical analysis was performed by MediStat with the use of SAP $^{\circledR}$ software.

\section{RESULTS}

\section{Clinical Results}

A positive result was defined as complete clinical clearance of all lesions 3 months after the last therapeutic session. In $36 \%$ of the acupuncture-treated patients, chronic warts disappeared, compared to $0 \%$ in the placebo group (Table 1). This was a significant difference between the groups.

\section{Serum Cytokines}

To determine the immune response induced by the treatment, concentrations of the cytokines IL-1, IL-6, IL-8, 
Table 2. Changes in Cytokine Concentrations Between Baseline and the End of the Experiment (Fourth Session)

\begin{tabular}{|c|c|c|c|c|c|}
\hline Marker & Group & $\begin{array}{c}\text { Average change } \\
(p g / m L \pm S T D)^{\mathrm{a}}\end{array}$ & $\begin{array}{l}\text { Range of } 95 \% \\
\text { scores }\end{array}$ & $\begin{array}{l}\mathrm{P} \text {-value for changes } \\
\text { within the group }\end{array}$ & $\begin{array}{c}\mathrm{P} \text {-value for changes } \\
\text { between groups }\end{array}$ \\
\hline \multirow[t]{2}{*}{ IL-1 } & Acupuncture & $-1.30 \pm 3.78$ & -4.21 to 1.60 & 0.2500 & \multirow[t]{2}{*}{0.8960} \\
\hline & Placebo & $-0.98 \pm 0.98$ & -2.20 to 0.23 & 0.1250 & \\
\hline \multirow[t]{2}{*}{ IL-6 } & Acupuncture & $-3.73 \pm 9.81$ & -11.27 to 3.80 & 0.2500 & \multirow[t]{2}{*}{0.2516} \\
\hline & Placebo & $5.14 \pm 10.35$ & -7.71 to 18.00 & 0.8125 & \\
\hline \multirow[t]{2}{*}{ IL-8 } & Acupuncture & $-0.37 \pm 1.52$ & -1.54 to 0.80 & 0.4258 & \multirow[t]{2}{*}{0.4381} \\
\hline & Placebo & $0.32 \pm 0.79$ & -0.66 to 1.30 & 0.6250 & \\
\hline \multirow[t]{2}{*}{ IL-10 } & Acupuncture & $-2.98 \pm 11.96$ & -12.18 to 6.21 & 0.3594 & \multirow[t]{2}{*}{0.0847} \\
\hline & Placebo & $7.77 \pm 10.70$ & -5.52 to 21.06 & 0.3125 & \\
\hline \multirow[t]{2}{*}{ IFN- $\gamma$} & Acupuncture & $-1.55 \pm 4.8$ & -4.95 to 1.86 & 0.3828 & \multirow[t]{2}{*}{1.0000} \\
\hline & Placebo & $-1.43 \pm 3.43$ & -5.69 to 2.82 & 0.3125 & \\
\hline \multirow[t]{2}{*}{ TNF- $\alpha$} & Acupuncture & $-0.55 \pm 6.78$ & -5.76 to 4.67 & 0.5703 & \multirow[t]{2}{*}{0.3055} \\
\hline & Placebo & $1.79 \pm 4.01$ & -3.19 to 6.77 & 0.6250 & \\
\hline
\end{tabular}

${ }^{\mathrm{a}}$ Average change: The average increase (+) or decrease (-) in cytokine concentration picograms per milliliter (pg/mL) between baseline and after fourth session \pm standard deviation (STD).

${ }^{\mathbf{b}}$ Range $95 \%$ of scores: The range where $95 \%$ of the group scores can be found.

${ }^{\mathrm{c}} P$-value for changes within the group: The level of significance of change within a group between the first and last sessions (signed-rank test).

${ }^{\mathrm{d}} P$-value for changes between groups: The level of significance of change between acupuncture and placebo (Wilcoxon nonparametric test).

IL, interleukin; IFN, interferon; TNF, tumor necrosis factor.

IL-10, INF- $\gamma$, and TNF- $\alpha$ were measured following each of the 4 clinical sessions. Six of the participants refused or were unable to have their blood drawn, and, therefore, some of the data are limited. Table 2 summarizes the changes in cytokine concentrations determined before the first session and after the fourth session.

For the cytokines IL-1, IL-6, IL-8, IL-10, and TNF- $\alpha$, a decrease was observed in the acupuncture versus the placebo group, but variability within and between groups was too high to establish significance. For the cytokine IFN- $\gamma$, there was no difference between the acupuncture and placebo group. For IL-10, the decreasing trend was close to significance. The greatest change in concentration was observed after the first session, with no elevation thereafter (Fig. 2).

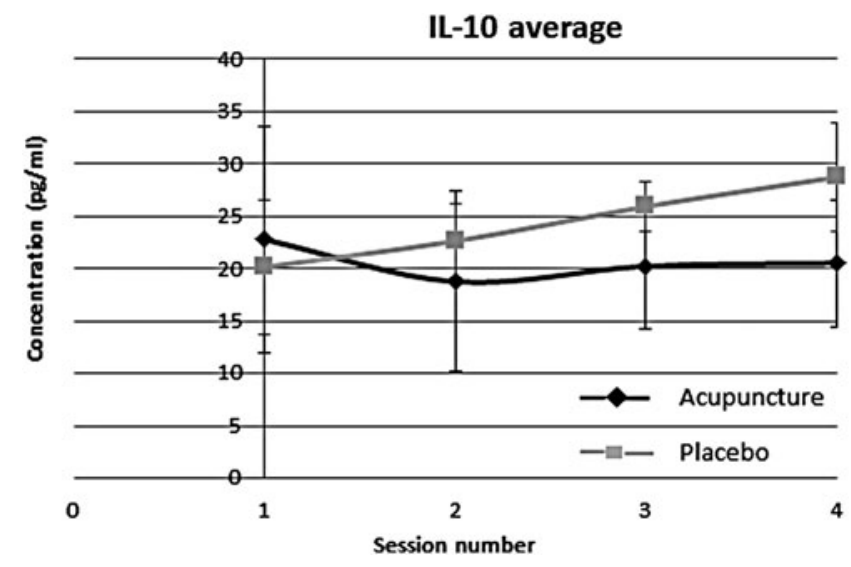

FIG. 2. Average changes in interleukin (IL)-10 blood concentrations throughout the experiment.

\section{T-Cell Subpopulations}

Distribution of CD4, CD8, and CD25 T-cells was measured after each of the 4 clinical sessions. The changes in immune-to-cell ratios of CD45:CD4, CD45:CD8, and CD4:CD25 between baseline in the first session and level after the fourth session are summarized in Table 3.

There was no observable difference between the acupuncture and placebo groups in the ratios between CD45:CD4, CD4:CD25, or CD45:CD8 subpopulations (Table 3).

\section{Evaluation of Link Between Clinical Results and Immunologic Findings}

To investigate the correlation between clinical outcomes and immunologic results, immunologic profiles of patients with clinical lesion clearance (LC; $n=4$ in acupuncture group) and nonclearance (non-LC; $n=9$ in acupuncture and placebo groups) were compared (Table 4). Figures 3A, 3B, and $3 \mathrm{C}$ present the average changes in concentration of cytokines IL-10, IL-8, and TNF- $\alpha$, respectively, in both groups.

For the cytokines IL-10, IL-8, and TNF- $\alpha$, there was a significant decrease in concentration in the LC versus the non-LC group despite variability within and between the groups. The greatest change in concentration was after the first session, and it was relatively stable thereafter (Fig. 3).

For the cytokines IL- 6 and IFN- $\gamma$, a similar trend was observed but variability within and between groups was too high to establish significance. For the cytokine IL-1 and for the T-cell subpopulations, there were no differences between the LC and non-LC groups (Fig. 3). 
Table 3. Changes in T-Cell Ratios Between Baseline and End of the Experiment (Fourth Session)

\begin{tabular}{llcccc}
\hline Marker & Group & Average change $(\% \pm S T D)^{\mathrm{a}}$ & Range $95 \%$ of scores $^{\mathrm{b}}$ & $\begin{array}{c}\text { P-value for change } \\
\text { within the group }^{\mathrm{c}}\end{array}$ & $\begin{array}{c}\text { P-value for changes } \\
\text { between groups }^{\mathrm{d}}\end{array}$ \\
\hline \multirow{2}{*}{$\mathrm{CD} 4$} & Acupuncture & $5.85 \pm 10.7$ & -3.11 to 14.81 & 0.2500 & 0.5225 \\
& Placebo & $6.10 \pm 10.7$ & -7.24 to 19.44 & 0.1875 & 1.0000 \\
$\mathrm{CD} 25$ & Acupuncture & $-1.91 \pm 3.54$ & -4.87 to 1.05 & 0.1953 & 0.6177 \\
& Placebo & $-1.06 \pm 1.99$ & -3.53 to 1.41 & 0.3750 & 0.7422 \\
& Acupuncture & $0.83 \pm 4.83$ & -3.20 to 4.87 & 0.6250 & \\
\hline
\end{tabular}

${ }^{a}$ Average increase or decrease in T-cell subpopulation between baseline and fourth session \pm standard deviation (STD).

${ }^{\mathrm{b}}$ Range in which $95 \%$ of the group scores can be found.

${ }^{c}$ Level of significance of change within a group (signed-rank test).

${ }^{\mathrm{d}}$ Level of significance of change between acupuncture and placebo groups (Wilcoxon nonparametric test).

A reduction in the concentrations of IL-10, IL-8, and TNF- $\alpha$ in the LC versus the non-LC group was observed, with the greatest change in concentration after the first session, and relative stability thereafter.

\section{Immunologic Profile of the LC Group}

The relationship between clinical results and immunologic findings (changes in cytokine profiles of the LC group, $n=4$ ) was evaluated. Figures $4 \mathrm{~A}, 4 \mathrm{~B}$, and $4 \mathrm{C}$ represent changes in concentrations of IL-10, TNF- $\alpha$, and IL-8, respectively, in participants $1,11,14$, and 17 .

A reduction in concentration of all three cytokines was observed in participants 1,11 , and 14. In participant 17 , the opposite trend was seen for cytokines IL-10 and TNF- $\alpha$, and the trend was inconsistent for IL-8.

In general, in the acupuncture versus the placebo group, there was a decrease in TNF- $\alpha$, IL- 6 , IL- 8 , and IL- 1 concentrations. In the case of IL-10, this trend was close to statistical significance, and for INF- $\gamma$, no difference was

Table 4. Changes in Immunologic Markers and Clinical Efficacy

\begin{tabular}{|c|c|c|c|c|c|}
\hline Immunologic marker & Clinical results & $\begin{array}{c}\text { Average change } \\
(\mathrm{pg} / \mathrm{mL}, \% \pm S T D)^{\mathrm{a}}\end{array}$ & $\begin{array}{l}\text { Range } 95 \% \\
\text { of scores }\end{array}$ & $\begin{array}{l}\mathrm{P} \text {-value for changes } \\
\text { within the group }\end{array}$ & $\begin{array}{c}\mathrm{P} \text {-value for changes } \\
\text { between groups }\end{array}$ \\
\hline \multirow[t]{2}{*}{ IL-1 } & Non-LC & $-1.09 \pm 3.72$ & -3.94 to 1.77 & 0.2031 & \multirow[t]{2}{*}{0.5007} \\
\hline & $\mathrm{LC}$ & $-1.60 \pm 1.49$ & -3.97 to 0.76 & 0.2500 & \\
\hline \multirow[t]{2}{*}{ IL-6 } & Non-LC & $1.38 \pm 11.25$ & -7.27 to 10.03 & 1.0000 & \multirow[t]{2}{*}{0.3357} \\
\hline & $\mathrm{LC}$ & $-7.18 \pm 7.05$ & -18.40 to 4.04 & 0.2500 & \\
\hline \multirow[t]{2}{*}{ IL-8 } & Non-LC & $0.35 \pm 0.47$ & -0.69 to 1.39 & 0.3594 & \multirow[t]{2}{*}{0.0593} \\
\hline & $\mathrm{LC}$ & $-1.26 \pm 0.47$ & -2.00 to -0.51 & 0.1250 & \\
\hline \multirow[t]{2}{*}{ IL-10 } & Non-LC & $4.69 \pm 10.27$ & -3.21 to 12.5 & 0.4961 & \multirow[t]{2}{*}{0.0777} \\
\hline & $\mathrm{LC}$ & $-11.29 \pm 8.34$ & -24.57 to 1.99 & 0.2500 & \\
\hline \multirow[t]{2}{*}{ IFN- $\gamma$} & Non-LC & $0.04 \pm 3.88$ & -3.20 to 3.29 & 1.0000 & \multirow[t]{2}{*}{0.1767} \\
\hline & $\mathrm{LC}$ & $-3.76 \pm 1.57$ & -6.25 to -1.2 & 0.1250 & \\
\hline \multirow[t]{2}{*}{ TNF- $\alpha$} & Non-LC & $2.08 \pm 5.37$ & -2.05 to 6.21 & 0.5703 & \multirow[t]{2}{*}{0.0193} \\
\hline & $\mathrm{LC}$ & $-5.42 \pm 2.26$ & -9.02 to -1.82 & 0.1250 & \\
\hline \multirow[t]{2}{*}{ CD4 } & Non-LC & $5.79 \pm 11.09$ & -2.74 to 14.32 & 0.2500 & \multirow[t]{2}{*}{1.0000} \\
\hline & $\mathrm{LC}$ & $7.57 \pm 11.42$ & -20.81 to 35.94 & 0.5000 & \\
\hline \multirow[t]{2}{*}{$\mathrm{CD} 25$} & Non-LC & $-2.00 \pm 3.44$ & -4.64 to 0.64 & 0.1055 & \multirow[t]{2}{*}{0.8567} \\
\hline & $\mathrm{LC}$ & $-0.83 \pm 1.68$ & -5.01 to 3.3 & 0.5000 & \\
\hline \multirow[t]{2}{*}{ CD8 } & Non-LC & $1.91 \pm 7.70$ & -4.01 to 7.83 & 0.9102 & \multirow[t]{2}{*}{0.4750} \\
\hline & $\mathrm{LC}$ & $-1.44 \pm 5.34$ & -14.71 to 11.8 & 0.7500 & \\
\hline
\end{tabular}

\footnotetext{
${ }^{a}$ Average increase or decrease in cytokine concentration picograms per milliliter ( $\left.\mathrm{pg} / \mathrm{mL}\right)$, or T-cell subpopulation (\%) between baseline and fourth session \pm standard deviation (STD).

${ }^{b}$ Range in which $95 \%$ of the group scores can be found.

${ }^{c}$ Level of significance of change within a group (signed-rank test).

${ }^{\mathrm{d}}$ Level of significance of change between lesion clearance (LC) and nonclearance (non-LC) groups (Wilcoxon nonparametric test). Statistical significance between the first and last session.

IL, interleukin; IFN, interferon; TNF, tumor necrosis factor.
} 

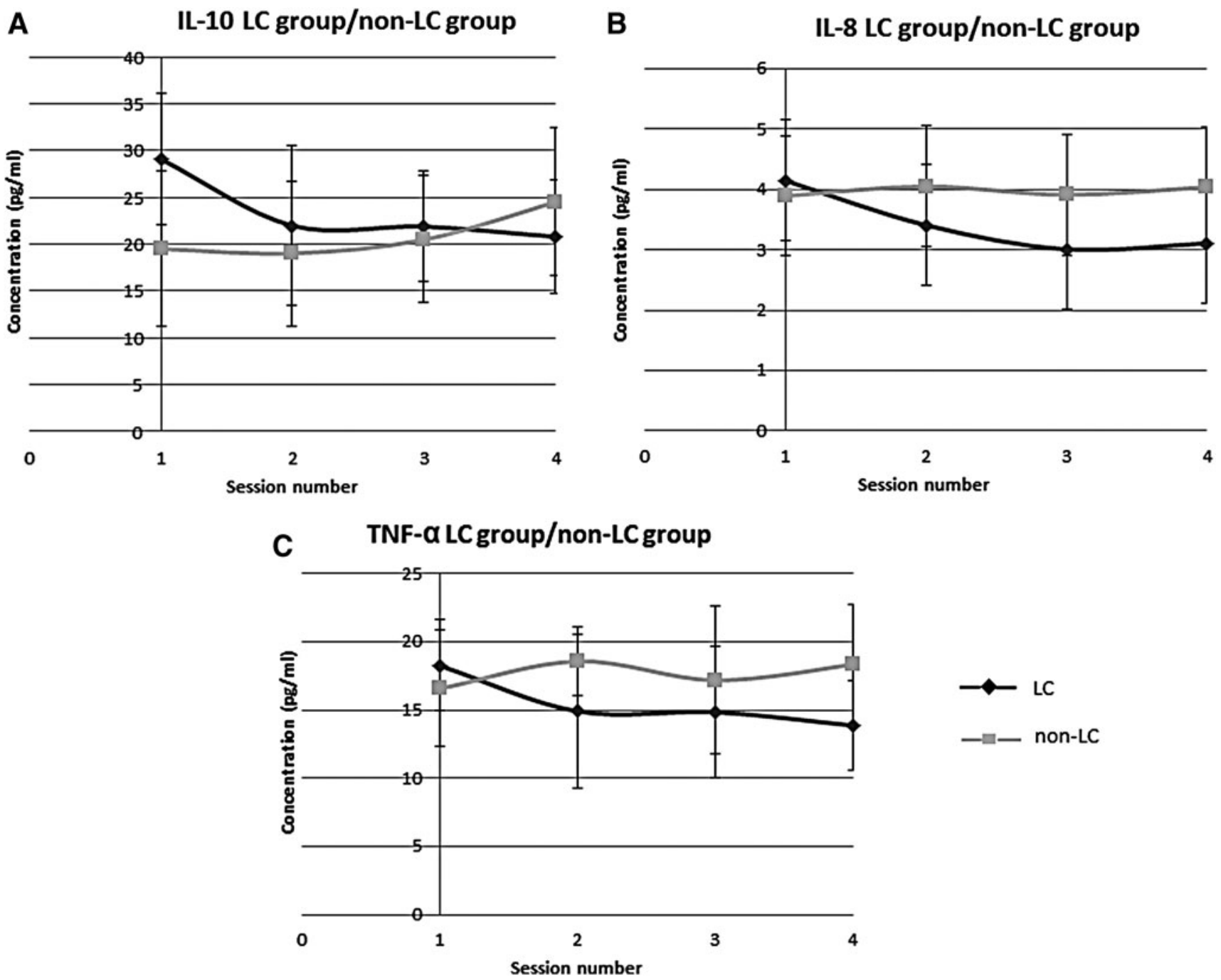

FIG. 3. (A) Average changes in concentrations of cytokine interleukin (IL)-10 in lesion-clearance (LC) and non-LC groups. (B) Average changes in concentration of cytokine IL-8 in LC and non-LC groups. (C) Average changes in concentration of cytokine tumor necrosis factor (TNF) $-\alpha$ in lesion clearance (LC). Error bars indicate standard deviation in each part.

observed (Table 2). With respect to LC, there was a statistically significant decrease in the concentrations of TNF- $\alpha$, IL-10, and IL-8 (Table 4, Fig. 3). A similar trend with no statistical significance was observed for IL-6 and INF- $\gamma$, and no trend was observed for IL-1 (Table 4). It is possible that, in a larger and more homogeneous group of participants, the findings would have shown more significance.

\section{DISCUSSION}

HPV infection has become a major public health concern, and recent research has detailed the virus-host interactions. It has been established that chronic HPV infection involves viral manipulation of the lesion's immunologic microenvi- ronment, including a change in the Th1/Th2 balance toward a decrease in Th1 cells and an increase in Th2 cells, as well as induction of secretion of cytokines that promote regulatory T-cells, a Th2 response, and angiogenesis. ${ }^{30-32}$ These facilitate a decline in efficacy of the key response for clearing the HPV infection. ${ }^{28,33,34}$ The hypothesis of the current study was that acupuncture treatment could help resolve chronic HPV infection via manipulation of the lesion's immunologic microenvironment by inducing activation of innate immunity, followed by activation of the acquired immune system, including modulation of Th1/Th2 ratio toward enhanced Th1. Very few studies have been published on the treatment of HPV with acupuncture, ${ }^{4,5}$ and no work has been published on the treatment of chronic HPV cases with acupuncture or, in particular, ELS acupuncture. 
A

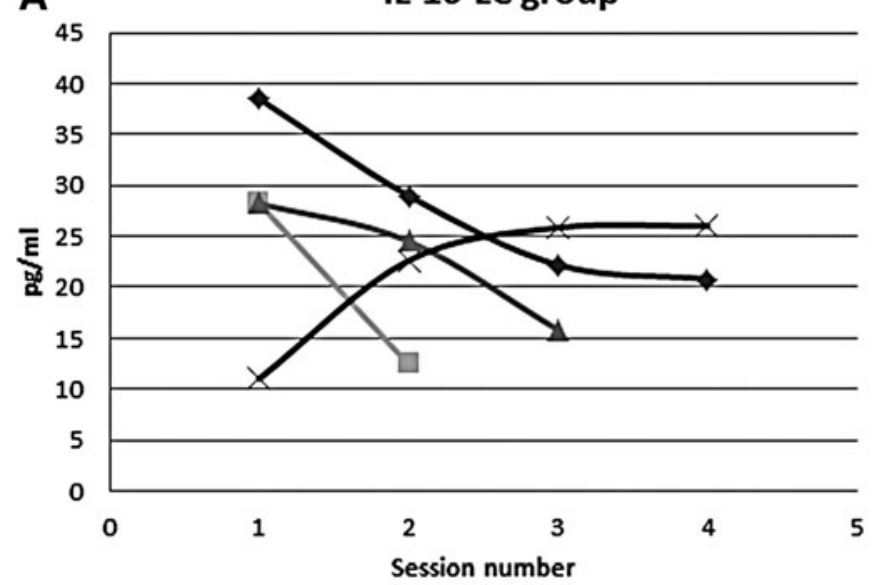

B

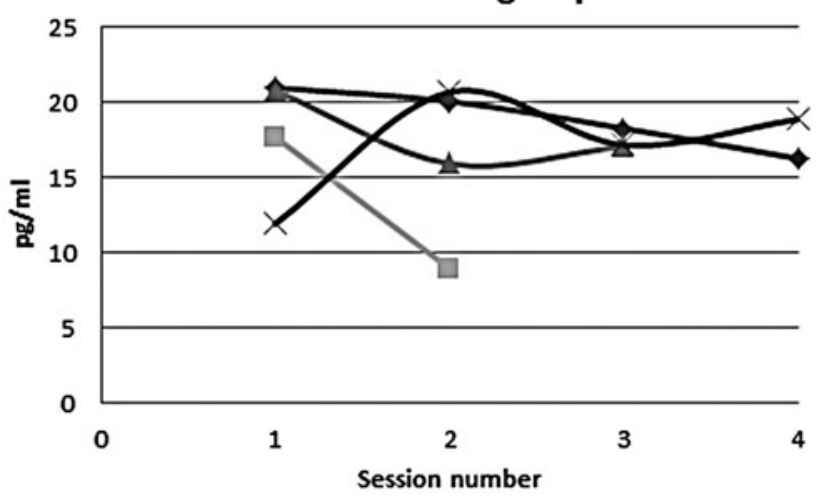

C

\section{IL-8 LC group}

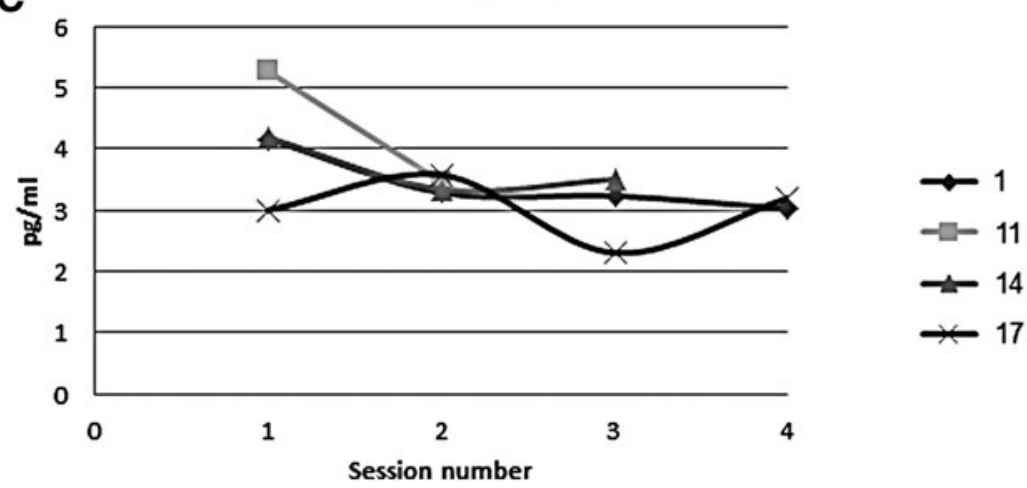

FIG. 4. Changes in cytokine concentrations (pg/mL) in the 4 participants $(1,11,14$, and 17) with lesion clearance (LC). Participants are presented separately. Only 2 samples were obtained from participant 11 (in the first and second sessions); 3 samples were obtained from participant 14 (in the first, second, and third sessions). (A) Interleukin (IL)-10 LC group. (B) Tumor necrosis factor (TNF) $-\alpha$ LC group. (C) IL-8 LC group.

The current authors determined the influence of ELS acupuncture by comparing levels of leukocytes and blood cytokines before and after treatment. The choice of cytokines for observation was based on reports of their involvement in the Th1/Th2 response, HPV infection, and a possible influence of acupuncture treatment on their levels according to the literature.

It is important to note that the group of participants in the study was relatively small $(N=18)$ and also widely heterogeneous in age, gender, and medical background. Therefore, the conclusions are based on trends of changes following treatments rather than absolute levels of cytokines and cells. Whereas serum concentrations of cytokines IL-1, IL-6, IL-8, IL-10, INF- $\gamma$, and TNF- $\alpha$ were similar for the treatment and placebo groups, a significant difference was found in a comparison of these parameters in patients with clinically successful (LC) versus unsuccessful (nonLC) outcomes.

INF- $\gamma$ and IL- 1 are key components in keratinocyte defense and are able to induce acquired immunity against HPV. ${ }^{1,29}$ It has been previously shown that acupuncture could influence IL-1 ${ }^{34,35}$ but not INF- $\gamma$ concentrations. However, in the current study, the concentrations of these cytokines were not significantly affected by acupuncture treatment or in relation to LC. IL-6 and IL-8 secreted in the early stages of the immune response downstream of IL-1 and INF- $\gamma$ act as proinflammatory cytokines. In advanced stages of the immune response, they have a regenerative, angiogenic effect. ${ }^{36,37}$

In this current study, the concentrations of these cytokines were reduced (significantly for IL-8) following acupuncture, and in correlation with LC. Other studies have shown that acupuncture might alter IL- 8 and IL-6 concentrations. ${ }^{35,38,39}$ It has been shown that HPV-infected cells within non-HPV tumors, such as skin and breast cancer, secrete IL-6 and IL-8, possibly supporting the tumor microenvironment. ${ }^{2,40}$

The reduction in TNF- $\alpha$ in relation to LC may be viewed as paradoxical, as TNF- $\alpha$ is a quintessential Th1 cytokine that is important in the body's defense against HPV. In contrast to IL-10, IL-8, and IL-6, TNF- $\alpha$ is not known to be involved in the HPV-induced lesion microenvironment. 
However, its involvement has been hypothesized in some types of cancer. ${ }^{31,41}$ Furthermore, chronic exposure to low levels of TNF- $\alpha$ may result in an antiapoptotic TNFmediated prosurvival pathway and angiogenesis. ${ }^{41}$ IL-10 has an anti-inflammatory effect in the Th1 immune response and a proinflammatory effect in the Th2 immune response. ${ }^{42}$ Increased levels of IL-10 might contribute to the establishment of chronic HPV infection by inhibiting the response of cytotoxic T-lymphocytes, the host's main tool for clearing HPV infection. ${ }^{28}$ Individuals with chronic HPV infection have been known to have high levels of IL-10 both locally and in the serum. Furthermore, high levels of IL-10 have been correlated with a higher risk of developing HPVrelated malignancy. ${ }^{34}$

In this work, a reduction in IL-10 concentration, close to statistical significance, was observed following acupuncture treatment (Table 2 and Fig. 2); this reduction was statistically significant in relation to LC (Table 4 and Fig. 3A). To investigate the relationship further between the clinical results and immunologic findings, profiles of cytokines IL-10, IL-8, and TNF- $\alpha$ in the LC group were evaluated. For 3 participants, there was a reduction in all three cytokines, whereas 1 participant had the opposite response (Fig. 4). However, this latter participant's cytokine levels were initially lower than the rest. The possibility of a particular acupuncture treatment resulting in opposite reactions in different individuals has rarely been documented and may be considered an inconsistency. ${ }^{43}$ However, such a phenomenon is quite likely according to ELS theory, as therapeutic intervention is considered a form of nondeterministic system reset. $^{44,45}$ The influence of acupuncture on IL-10 concentrations has been shown in other studies as well. The effect of acupuncture treatment on clinical reduction of symptoms of allergic diseases has been correlated with a decrease in IL-10 concentrations. $^{35}$ Similar results have been reported in acupuncture treatment of rheumatoid arthritis. $^{36}$

On the one hand, the involvement of T-cells in the elimination of HPV-related lesions has been found to be the result of a cytotoxic CD8 T-cell response ${ }^{1,27,46}$; on the other hand, an important mechanism of immune evasion by HPV is the recruitment of CD25 regulatory T-cells. ${ }^{1,47}$ Other studies have reported that acupuncture treatment influences the CD4 subpopulation, ${ }^{43}$ and CD4:CD8 ratio. ${ }^{48}$ In this current study, no statistically significant changes were observed in CD4, CD8, or CD25 cell populations between the acupuncture and placebo groups (Table 3 ) or in relation to LC (Table 4).

\section{CONCLUSIONS}

This study investigated acupuncture treatment against chronic HPV lesions and the related immune modulation.
The treatment seemed to have an anti-inflammatory effect. In relation to cytokines IL- 1 and INF- $\gamma$, it is important to note that the participants in the study all had chronic persistent HPV infections, and, in this advanced stage of infection, the innate response may not be relevant. However, the immune microenvironment of HPV lesions can be characterized as a weak chronic inflammation with chronic levels of IL-6, IL-8, and IL-10. ${ }^{28,32}$ Thus, it is possible that the acupuncture treatment acted to counter the lesions' immunologic microenvironments. More research, with a greater number and a more-homogeneous group of participants is needed.

To summarize, this study shows the feasibility of treating chronic HPV lesions with acupuncture with a limited rate of success. As acupuncture did not involve direct assault on the lesions, as is usually the case with other treatments, it can be combined with other, more-conventional methods. Therefore, these results, although moderate, should be sufficient to justify further research. The study found a correlation between lesion regression following acupuncture treatment and immune characteristics, suggesting a mechanism for acupuncture's effect.

\section{AUTHOR DISCLOSURE STATEMENT}

No competing financial interests exist.

\section{REFERENCES}

1. Stanley MA. Immune responses to human papilloma viruses. Indian J Med Res. 2009;130(3):266-276.

2. Bernat-García J, Morales Suárez-Varela M, Vilata-Corell JJ, Marquina-Vila A. Detection of human papillomavirus in nonmelanoma skin cancer lesions and healthy perilesional skin in kidney transplant recipients and immunocompetent patients. Actas Dermosifiliogr. 2014;105(3):286-294.

3. Lipke MM. An armamentarium of wart treatments. Clin Med Res. 2006;4(4):273-293.

4. Ursini T, Polilli E, Congedo G, et al. Complete healing of a giant wart in a severely immune-compromised patient with HIV infection treated with acupuncture. Case Rep Dermatol. 2011;3(2):175-180.

5. Ning S, Li F, Qian L, et al. The successful treatment of flat warts with auricular acupuncture. Int J Dermatol. 2012;51(2): 211-215.

6. UKHealthCentre. Types of Acupuncture. Online document at: www.healthcentre.org.uk/acupuncture/types-of-acupuncture .html Accessed May 5, 2017.

7. Mussat M, Bégin ME, Bureau JP. A constructionist model predicting the emergence, complementarity and classification of the nucleotide bases. Med Hypotheses. 1998;51(6):511-523.

8. Introduction to SEA. Online document at: www.trigrams.org/ index.php/systemsmenu/53-referencessection/systems/190systemssea1 Accessed May 5, 2017. 
9. Yuan Q, Guo T, Liu L, Sun F, Zhang Y. Traditional Chinese Medicine for neck pain and low back pain: A systematic review and meta-analysis. PLoS One. 2015;10(2): e0117146.

10. Lo MY, Lin JG, Ong MW, Sun WZ. Cerebral hemodynamic responses to acupuncture in migraine patients: A systematic review. J Tradit Complement Med. 2015;3(4): 213-220.

11. Zhang JH, Wang D, Liu M. Overview of systematic reviews and meta-analyses of acupuncture for stroke. Neuroepidemiology. 2014;42(1):50-58.

12. Sniezek DP, Siddiqui IJ. Acupuncture for treating anxiety and depression in women: A clinical systematic review. Med Acupunct. 2013;25(3):164-172.

13. Sherman K, Sun J, Lin C. Acupuncture for insomnia. Focus Altern Complement Ther. 2010;15(2):293-294.

14. Rathbone J, Xia J. Acupuncture for schizophrenia. Cochrane Database Syst Rev. 2005;4:CD005475.

15. Cochrane S, Smith CA, Possamai-Inesedy A, Bensoussan A. Acupuncture and women's health: An overview of the role of acupuncture and its clinical management in women's reproductive health. Int J Womens Health. 2014;6: 313-325.

16. Yamaguchi N, Takahashi T, Sakuma M, et al. Acupuncture regulates leukocyte subpopulations in human peripheral blood. Evid-Based Complement Alternat Med. 2007;4(4): 447-453.

17. Chen Y-W, Wang H-H. The effectiveness of acupressure on relieving pain: A systematic review. Pain Manage Nurs. 2014;15(2):539-550.

18. Feng S, Han M, Fan Y, et al. Acupuncture for the treatment of allergic rhinitis: A systematic review and meta-analysis. Am J Rhinol Allergy. 2015;29(1):57-62.

19. Liu CF, Chien LW. Efficacy of acupuncture in children with asthma: A systematic review. Ital J Pediatr. 2015;41:48.

20. Gamus D. Cholinergic anti-inflammatory pathway of some non-pharmacological therapies of complementary medicine: Possible implications for treatment of rheumatic and autoimmune diseases [in Hebrew]. Harefuah. 2011;150(8):660663,687 .

21. Silvério-Lopes S, Gonçalves MP, Mota D. Acupuncture in Modulation of Immunity. Online document at: www. intechopen.com/books/acupuncture-in-modern-medicine/ acupuncture-in-modulation-of-immunity Accessed May 5, 2017.

22. Ouyang B-S, Gao J, Che J-L, et al. Effect of electroacupuncture on tumor necrosis factor- $\alpha$ and vascular endothelial growth factor in peripheral blood and joint synovia of patients with rheumatoid arthritis. Chin J Integr Med. 2011; 17(7):505-509.

23. Gui J, Xiong F, Li J, Huang G. Effects of acupuncture on Th1, Th2 cytokines in rats of implantation failure. Evid-Based Complement Alternat Med. 2012;2012:893023.

24. Wu XL, Wang YL, Sun JH, et al. Clinical observation on acupuncture for diarrhea-predominant irritable bowel syndrome patients in syndrome of Liver-Stagnation and SpleenDeficiency and its impact on Th1/Th2 [in Chinese]. Zhongguo Zhen Jiu. 2013;33(12):1057-1060.
25. Carneiro ER, Xavier RAN, De Castro MAP, Do Nascimento CMO, Silveira VLF. Electroacupuncture promotes a decrease in inflammatory response associated with Th1/Th2 cytokines, nitric oxide and leukotriene B4 modulation in experimental asthma. Cytokine. 2010;50(3):335-340.

26. Kwang S, Bae H. Autonomic Neuroscience : Basic and Clinical Acupuncture and immune modulation. Auton Neurosci Basic Clin. 2010;157(1-2):38-41.

27. Best SR, Niparko KJ, Pai SI. Biology of HPV infection and immune therapy for HPV-related head and neck cancers. Otolaryngol Clin North Am. 2012;45(4):807-822.

28. Amador-Molina A, Hernández-Valencia JF, Lamoyi E, Contreras-Paredes A, Lizano M. Role of innate immunity against human papillomavirus (HPV) infections and effect of adjuvants in promoting specific immune response. Viruses. 2013;5(11):2624-2642.

29. Stanley MA. Epithelial cell responses to infection with human papillomavirus. Clin Microbiol Rev. 2012;25(2):215222.

30. Bais AG, Beckmann I, Lindemans J, et al. A shift to a peripheral Th2-type cytokine pattern during the carcinogenesis of cervical cancer becomes manifest in CIN III lesions. J Clin Pathol. 2005;58(10):1096-1100.

31. Landskron G, De la Fuente M, Thuwajit P, Thuwajit C, Hermoso MA. Chronic inflammation and cytokines in the tumor microenvironment. J Immunol Res. 2014;2014: 149185.

32. Mangino G, Chiantore MV, Iuliano M, Fiorucci G, Romeo G. Inflammatory microenvironment and human papillomavirusinduced carcinogenesis. Cytokine Growth Factor Rev. 2016; 30:103-111.

33. Bleotu C, Chifiriuc MC, Grigore R, et al. Investigation of Th1/ Th2 cytokine profiles in patients with laryngo-pharyngeal, HPVpositive cancers. Eur Arch Otorhinolaryngol. 2013;270(2): 711-718.

34. Ouyang B-S, Che J-L, Gao J, et al. Effects of electroacupuncture and simple acupuncture on changes of IL-1, IL4, IL-6 and IL-10 in peripheral blood and joint fluid in patients with rheumatoid arthritis [in Chinese]. Zhongguo Zhen Jiu. 2010;30(10):840-844.

35. McDonald JL, Cripps AW, Smith PK, Smith CA, Xue CC, Golianu B. The anti-inflammatory effects of acupuncture and their relevance to allergic rhinitis: A narrative review and proposed model. Evid-Based Complement Alternat Med. 2013; 2013:591796.

36. Waugh DJJ, Wilson C. The interleukin- 8 pathway in cancer. Clin Cancer Res. 2008;14(21):6735-6741.

37. Scheller J, Chalaris A, Schmidt-Arras D, Rose-John S. The pro- and anti-inflammatory properties of the cytokine interleukin-6. Biochim Biophys Acta. 2011;1813(5):878-888.

38. Joos S, Schott C, Zou H, Daniel V, Martin E. Immunomodulatory effects of acupuncture in the treatment of allergic asthma: A randomized controlled study. J Altern Complement Med. 2000;6(6):519-525.

39. Yuan S-Y, Qin Z, Liu D-S, Yin W-Q, Zhang Z-L, Li S-G. Acupuncture for chronic pelvic pain syndromes (CPPS) and its effect on cytokines in prostatic fluid. Zhongguo Zhen Jiu. 2011;31(1):11-14. 
40. Glenn WK, Heng B, Delprado W, Iacopetta B, Whitaker NJ, Lawson JS. Epstein-Barr virus, human papillomavirus and mouse mammary tumour virus as multiple viruses in breast cancer. PLoS One. 2012;7(11):e48788.

41. Tse BWC, Scott KF, Russell PJ. Paradoxical roles of tumour necrosis factor-alpha in prostate cancer biology. Prostate Cancer. 2012;2012:128965.

42. Sabat R, Grütz G, Warszawska K, et al. Biology of interleukin-10. Cytokine Growth Factor Rev. 2010;21(5): 331-344.

43. Takahashi T, Sumino H, Kanda T, Yamaguchi N. Acupuncture modifies immune cells. J Exp Clin Med. 2009;1(1): $17-22$.

44. Helms J. Acupuncture Energetics: A Clinical Approach for Physicians. Berkeley: Medical Acupuncture Publishers; 1995.

45. Trigrams Acupuncture. About Trigrams. Online document at: http://trigrams.org/index.php/about-trigrams Accessed May 5, 2017.
46. Deligeoroglou E, Giannouli A, Athanasopoulos N, et al. HPV infection: Immunological aspects and their utility in future therapy. Infect Dis Obstet Gynecol. 2013;2013:540850.

47. Øvestad IT, Gudlaugsson E, Skaland I, et al. Local immune response in the microenvironment of CIN2-3 with and without spontaneous regression. Mod Pathol. 2010;23(9):1231-1240.

48. Kou W, Bell JD, Gareus I, et al. Repeated acupuncture treatment affects leukocyte circulation in healthy young male subjects: A randomized single-blind two-period crossover study. Brain Behav Immun. 2005;19(4):318-324.

Address correspondence to: Jacob Pitcovski, PhD MIGAL_Galilee Technology Center P.O. Box 831

Kiryat Shmona 11016

Israel

E-mail: jp@migal.org.il 